Linha D'Água (Online), São Paulo, v. 29, n. 1, p. 181-200, jun. 2016

\title{
COESÃO, COERÊNCIA E CONSTRUÇÃO DE OBJETOS DE DISCURSO: VISLUMBRANDO UMA PERSPECTIVA SOCIOCOGNITIVA E INTERACIONAL PARA O ENSINO DA PRODUÇÃO ESCRITA
}

\author{
COHESION, COHERENCE, AND THE CONSTRUCTION OF \\ DISCOURSE OBJECTS: A GLIMPSE OF A SOCIOCOGNITIVE AND \\ INTERACTIONAL PERSPECTIVE ON TEACHING OF WRITING
}

\author{
Silvia Augusta de Barros Albert* \\ Grupo Educacional Cruzeiro do Sul, São Paulo, SP, Brasil
}

\begin{abstract}
Resumo: Este artigo tem por objefivo mostrar como os atuais estudos teóricos da Lingúistica Textual, de perspectiva sociocognitiva e interacional, a abordar as noç̦ées de coes̃̃o, coerência e referenciação, podem colaborar para a prática pedagógica no que tange 0 ensino e aprendizagem da escrita, tendo em vista o desenvolvimento da proficiência escritora. Consideramos a coesão e a coerência como critérios de textualizacạ̃o, admitindo não só a interdependência entre eles, mas também a sua codeterminação ao processo de referenciaç̦ão. Dessa perspectiva, a construção da coesão e da coerência é dinâmica, processual e ocorre por meio de inferências e estratégias cognitivas para os quais concorrem as marcas lingúisticas, os conhecimentos prévios, a interacacão entre os interlocutores e 0 contexto. Destacamos a selecção das formas nominais, na construcạ̃o da representação de objetos de discurso, relacionando-as ao projeto de dizer do locutor em redaç̦ées de vestibular. Defendemos, assim, que a referenciação, ao construir representaçōes para objetos de discurso, consititui uma base para a estruturacção do texto e providencia pistas para a produção de sentidos na escrita. Respaldamo-nos, neste trabalho, principalmente, nos estudos de Koch (2006), Marcuschi (2006; 2007; 2008), Cavalcante et al. (2010) e Bentes (2012).
\end{abstract}

Palavras-chave: Produção textual; Ensino; Coesão e coerência; Referenciação; Redação de vestibular.

\begin{abstract}
This article aims at presenting how current theoretical advances on Text Linguistics in its sociocognifive and interactional perspective, by approaching the concepts of cohesion, coherence, and referentiation, may contribute to the pedagogical practice regarding the teaching and learning of writing vis-a-vis the development of writing proficiency. Hence, cohesion and coherence are considered the criteria for textualization, and both their reciprocity and their mutual determination in the referentiation process are here acknowledged. From this point view, the construction of cohesion and coherence is a dynamic process that occurs via inferences and cognitive devices to which the linguistic marks, the speakers' interaction, and the context contribute. Accordingly, a selection of nominal forms in the building of representations of discourse objects is to be highlighted and related to the project of saying enounced by the herald of college entrance essays. The hypothesis is thus that, by constructing representations of discourse objects, referentiation establishes a groundwork for text structuring and provides hints to produce meaning in writing. The main studies this article is grounded on are Koch (2006), Marcuschi (2006; 2007; 2008), Cavalcante et al. (2010), and Bentes (2012).
\end{abstract}

Keywords: Text Production; Teaching; Cohesion and Coherence; Referentiation; College Entrance Essays.

* Coordenadora dos cursos de Letras, na modalidade a distância, do Grupo Educacional Cruzeiro do Sul, São Paulo, São Paulo, Brasil; silvia.augusta.albert@gmail.com 
Linha D'Água (Online), São Paulo, v. 29, n. 1, p. 181-200, jun. 2016

\section{Introdução}

Em nossa experiência em sala de aula no ensino básico, atuando como professora de Língua Portuguesa, deparamo-nos frequentemente com textos de alunos que tornam difícil a tarefa de atribuição de sentidos por parte do leitor. Em muitos casos, esse resultado mal sucedido deve-se ao estabelecimento precário da coesão e da coerência nesses textos, por parte do produtor.

Além disso, na interação com professores de língua materna, em cursos de formação, constatamos sua insatisfação em relação às intervenções realizadas tanto no processo de produção escrita quanto nos momentos de avaliação, de forma a auxiliar os alunos a vencer um desafio específico da escrita: produzir um texto coeso e coerente.

Em geral, observamos, no processo de avaliação, que a intervenção do professor nas devolutivas aos alunos se limita a frases como "esse texto não faz sentido"; "falta clareza"; "texto incoerente", "não há ligação entre ideias e partes do texto". Ocorre que essas indicações pouco orientam "esses aprendizes da palavra escrita" para a revisão e para a reescrita. Sendo assim, é provável que, nos textos posteriores desses discentes, não haja qualquer avanço em relação a tais aspectos e o ciclo se repita: mais textos "sem sentido" virão para a correção e a avaliação do professor.

A partir dessa constatação e de nossas inquietações, procuramos avançar na compreensão dos conceitos de coesão e coerência, com base nos estudos da Linguística Textual, de perspectiva sociocognitiva e interacional, e apresentar suas implicações para o ensino e aprendizagem da produção escrita, no sentido de orientar esse processo para o desenvolvimento da proficiência escritora. Para cumprir nossos objetivos, este artigo se divide em três partes, seguidas da conclusão:

1- na primeira, apresentamos a agenda atual dos estudos que tratam da relação entre texto e ensino, na perspectiva de autores como Rojo e Cordeiro (2004), Marcuschi (2008), Koch (2014[2008]), Koch e Elias (2011) e Gomes-Santos et al.(2010), com o intuito de enfatizar a pertinência dessa relação e dos percursos teóricos que a embasam;

2- na segunda, destacamos os postulados teóricos de autores como Van Dijk (2011[1992]), Koch (2006), Marcuschi (2006; 2007; 2008), Cavalcante et al. (2010) e Bentes (2012), que indicam um redimensionamento na conceituação de dois critérios de textualização, coesão e coerência, nos estudos da LT, e sua codeterminação à referenciação, retomando a relação entre texto e contexto e evidenciando a importância da cognição social para a produção de sentidos; 
Linha D'Água (Online), São Paulo, v. 29, n. 1, p. 181-200, jun. 2016

3- na terceira, realizamos a análise de duas redações de vestibular, a título de exemplificação, para ilustrar como esses princípios teóricos orientam um novo olhar para a produção escrita de alunos que encerram sua formação básica na escola, destacando a referenciação, em sua relação com a coesão e a coerência, como uma estratégia textual-discursiva para a produção de sentidos; e

4- na conclusão, refletimos sobre as implicações de uma abordagem sociocognitiva e interacional da coesão e da coerência para o ensino e aprendizagem da produção escrita, com vistas ao desenvolvimento da proficiência escritora no ensino básico.

\section{A relação texto e ensino, de uma perspectiva sociocognitiva e interacional}

Atualmente, é fato que o ensino de produção de textos é tarefa primordial da disciplina de Língua Portuguesa na educação básica. Rojo e Cordeiro (2004) atestam que o texto - como conjunto dos domínios de aprendizagem - leitura e produção ou como objeto de ensino - é a base do ensino e aprendizagem de língua materna, princípio que vem sendo afirmado desde a década de 1980 .

Para as autoras, primeiramente o texto foi tomado como um material ou objeto empírico que propiciava atividades de leitura, de produção e de análise linguística. Posteriormente, passou-se a tomar o texto como suporte para o desenvolvimento de estratégias e habilidades de leitura. Dessa perspectiva, o texto torna-se objeto de ensino dos eixos procedimentais e ocorre uma gramaticalização dos eixos de uso, passando o texto a ser pretexto para estudos gramaticais.

Várias foram as críticas a essa inserção do texto nas práticas escolares, que levaram, como postulam Rojo e Cordeiro (2004, p. 10), a "uma virada discursiva ou enunciativa no que diz respeito ao enfoque dos textos e de seus usos em sala de aula". Essa virada, relacionada aos trabalhos de pesquisa sobre leitura e produção de texto em diversos países, propiciou o enfoque em sala de aula do texto em seu funcionamento e contexto de produção/leitura, procurando evidenciar mais as significações geradas do que as propriedades formais. No Brasil, essa proposta passou a vigorar com mais força a partir de 1997/1998, quando se oficializaram os Parâmetros Curriculares Nacionais (Doravante PCN).

Nessa mesma direção, Gomes-Santos et al.(2010) confirmam essa aproximação dos estudos textuais brasileiros com a questão do ensino-aprendizagem de língua na escola, desde o final da década de 1970 e início dos anos de 1980, admitindo ser o texto um ponto de partida e de chegada para o trabalho da língua em sala de aula. Marcuschi (2008) reitera esse postulado ao afirmar que "o ensino de língua deve dar-se através de textos” (MARCUSCHI, 2008, p. 51). 
Sabemos também que, hodiernamente, essa prática é consenso e está estabelecida na escola, motivada e amparada por orientação dos PCN. Marcuschi (2008), no entanto, adverte que o ponto central está "no modo como isto é posto em prática, já que muitas são as formas de se trabalhar com o texto" (MARCUSCHI, 2008, p. 51). Essa posição é corroborada por Gomes-Santos et al.(2010) ao indagarem como os estudos no campo do texto, sobre leitura e escrita, estão vinculados ao ensino (GOMES-SANTOS et al., 2010, p. 317).

Esses autores destacam, ainda, as diferentes concepções de texto, procedentes das pesquisas em LT, desde a década de 1960 - abordagem sintático-semântica considerando o texto como frase completa ou signo linguístico - até a década de 1990, marcada pela virada discursiva, de perspectiva bakhtiniana, em que se adotou a concepção sociocognitiva e interacional e dialógica da língua. Só a partir de então, o texto, segundo Koch (2014[2008]), "passa a ser considerado o próprio lugar da interação e os interlocutores, sujeitos ativos que - dialogicamente - nele se constroem e por ele são construídos" (KOCH, 2014[2008], p. 21).

A partir dos postulados mais atuais sobre o conceito de texto, podemos perceber que se amplia bastante o horizonte do ensino e da aprendizagem da leitura e da escrita, introduzindo-se aspectos como a interação, as práticas comunicativas (gêneros e sequências textuais), a contextualização, a progressão referencial, a progressão sequencial e a coerência.

A concepção de texto, nos postulados aqui elencados, aliada ao conceito de gêneros, vem ao encontro das propostas dos PCN para leitura e produção de textos como base para a formação do aluno. Vale destacar que, nessa perspectiva, assumese também uma concepção de língua não homogênea. Para Marcuschi (2008), a língua "é uma atividade interativa, social e mental que estrutura nosso conhecimento e permite que nosso conhecimento seja estruturado." Para o autor, a língua não é um sistema abstrato e homogêneo, mas "heterogênea, social, histórica, cognitiva, indeterminada, variável, interativa e situada" (MARCUSCHI, 2008, p. 65).

A partir dessa concepção interacional e dialógica da língua, tanto quem escreve quanto aquele para quem se escreve são vistos, de acordo com Koch e Elias (2011, p. 34), como sujeitos ativos, "atores/construtores sociais". As autoras postulam, ainda, que ocorre no texto toda sorte de implícitos que só serão traduzidos quando se leva em conta, como pano de fundo, o contexto sociocognitivo dos participantes da interação, que consiste em todos os tipos de conhecimentos (enciclopédico, sociointeracional, procedural, textual etc.).

No caso da escrita, esses conhecimentos são levantados pelo sujeito produtor do texto e devem ser compartilhados com o(s) seu(s) interlocutor(es). Evidencia-se, 
Linha D'Água (Online), São Paulo, v. 29, n. 1, p. 181-200, jun. 2016

pois, que o sentido da escrita depende dessa interação e não é resultado apenas do uso do código e das intenções do escritor.

Tomada nessa perspectiva, de acordo com Koch e Elias (2011, p. 34), a escrita é uma atividade que demanda o uso de estratégias por parte do produtor que deve considerar: i. a ativação de conhecimentos sobre a situação comunicativa, ii. seleção, organização e desenvolvimento das ideias que garanta a continuidade do tema e sua progressão, iii. balanceamento entre informações implícitas e explícitas, levando em conta o compartilhamento de informações com o leitor, iv. revisão da escrita ao longo do processo, guiada por seus objetivos e pela interação pretendida com o leitor.

Essa demanda de estratégias configura a necessidade de desenvolver no produtor de texto uma competência comunicativa, o que constitui uma das grandes contribuições da LT no que concerne ao ensino e à aprendizagem da escrita (GOMES-SANTOS et al., 2010, p. 323). Vale lembrar que a escrita e os sentidos que ela propõe manifestam-se, conforme assevera Marcuschi (2008, p. 154), "sempre por meio de textos realizados em algum tipo de gênero" e, ainda, que a noção de gênero nos remete ao uso da linguagem em práticas sociais de escrita em que se revela uma interlocução, marcada social e historicamente, em dada situação de comunicação.

Essas considerações e contribuições da LT para o ensino evidenciam que a abordagem dos gêneros na escola deveria, como postulam os PCN, caracterizar-se por uma sistematização coerente e uma reflexão sobre os papéis dos interlocutores, os objetivos do texto e as estratégias necessárias para lê-lo/produzi-lo (GOMESSANTOS et al., 2010, p. 324).

No entanto, sabemos por nossa experiência com manuais didáticos, em sala de aula, que embora haja nessas publicações coletâneas de textos que contemplam os diferentes gêneros, nem sempre o trabalho proposto prioriza os domínios discursivos, enfatizando mais as tipologias, fundamentando-se numa concepção de língua mais normativa. Posicionando-se contrariamente, Marcuschi (2008) assevera: "a escola não ensina língua, mas usos da língua e formas não corriqueiras de comunicação escrita e oral” (MARCUSCHI, 2008, p. 55).

Essas constatações e alertas reafirmam nossas preocupações e inquietações, que expusemos na introdução deste artigo. As transformações necessárias na prática de sala de aula parecem não ter saído das páginas dos PCN, efetivamente. A nosso ver, há um discurso apregoado e não compreendido em seus aspectos essenciais, além de uma carta de (boas) intenções que não chegou aos destinatários. Concordamos, portanto, com Brandão (2003, p. 17) quando assevera que "para muitos o texto ainda não chegou na sua dimensão textual-discursiva”.

Nessa primeira parte, vimos que o ensino e a aprendizagem da escrita pressupõem uma concepção dialógica, heterogênea e interativa da língua, uma noção de 
Linha D'Água (Online), São Paulo, v. 29, n. 1, p. 181-200, jun. 2016

texto que engloba aspectos linguísticos e contextuais, além da participação de sujeitos ativos, situados sócio-histórica e culturalmente e inseridos numa dada prática social.

Constatamos também que, embora os estudos textuais, de uma perspectiva sociocognitiva e interacional, tenham se desenvolvido nos trabalhos de pesquisadores brasileiros e estrangeiros e procurado se aproximar do campo do ensino, ainda há fragilidades e descompassos entre a teoria, elaborada e divulgada nos estudos acadêmicos, e a prática vivenciada em sala de aula.

Na próxima seção, focalizamos o redimensionamento das noções de coesão e coerência, considerando sua interdependência e codeterminação com a referenciação. Cumpre ratificar que nosso propósito é abordar a importância desse redimensionamento, tendo em vista o ensino e a aprendizagem da escrita.

\section{Coesão e coerência - critérios de textualização para a produção de sentidos}

A concepção da escrita como produção textual, que exige do produtor a ativação de conhecimentos e a mobilização de estratégias (Koch e Elias, 2011, p. 34), remete à noção de texto postulada por Beaugrande (1997): um evento comunicativo para o qual concorrem aspectos linguísticos, culturais, sociais e cognitivos.

Essa definição trata do caráter duplo do texto enquanto artefato linguístico e processo sociocultural. $\mathrm{O}$ autor concebe a textualidade como um princípio de duplo alcance: tanto vista como a "qualidade de todos os textos" como uma condição de um empreendimento humano, quando o texto é textualizado, ou seja, quando o artefato é produzido ou recebido como texto (BENTES E REZENDE, 2014, p. 144).

Nesse sentido, assumimos a coesão e a coerência como critérios de textualização, respaldados em Marcuschi (2008), por constituírem-se "mais como critérios de acesso à construção de sentidos do que princípios de boa formação textual" (MARCUSCHI, 2008, p. 97). Sendo assim, a textualidade depende, de modo geral, de sua condição de processabilidade cognitiva e discursiva.

De acordo com Koch (2006), as noções de coesão e a coerência foram sofrendo alterações significativas à medida que se diferenciavam as noções de texto. A linguista aponta como principais modificações: i. a diferenciação dos dois conceitos, que praticamente se confundiam nas análises transfrásticas; ii. a constatação de que a coesão não é condição necessária nem suficiente para a coerência, já que esta não se encontra no texto, mas se constrói a partir dele, na situação interativa; iii. $\mathrm{O}$ fato de existir uma interdependência entre os dois conceitos, pois nem sempre a coesão se estabelece entre elementos presentes no texto, sendo necessário recorrer 
Linha D'Água (Online), São Paulo, v. 29, n. 1, p. 181-200, jun. 2016

a elementos contextuais, em particular da ordem sociocognitiva e interacional, o que conduz ao campo da coerência (KOCH, 2006, p. 46).

A seguir, elencamos estudos textuais de diferentes pesquisadores, de uma perspectiva sociocognitiva e interacional, que tratam da coesão e da coerência de forma mais discursiva, redimensionando-as, não as atrelando à superfície do texto ou às relações lógico-semânticas, como encontramos nas propostas teóricas anteriores à década de oitenta nos estudos da linguagem/texto. Esse fato vem confirmar os avanços na abordagem e nas análises, em relação a esses dois critérios de textualização. Acreditamos que esses postulados teóricos contribuam para a orientação do processamento textual e, consequentemente, para a orientação do ensino e da aprendizagem da escrita.

Para introduzir esse redimensionamento das noções de coesão e coerência, retomamos Van Dijk (2011[1992]) por seus estudos pioneiros no campo da teoria e análise do discurso/ texto e por ele ter construído uma obra de referência para o trabalho com modelos cognitivos de processamento de discurso.

No desenvolvimento de sua teoria sobre modelos cognitivos, Van Dijk (2011[1992]) assevera que o uso do conhecimento é estratégico e depende dos objetivos do usuário, da quantidade de conhecimento disponível no texto e no contexto, além do nível de processamento exigido para a compreensão. $\mathrm{O}$ autor afirma, ainda, que as crenças e avaliações pessoais são necessárias para estabelecer certos tipos de coerência local e global.

Para Van Djik, a noção de coerência dificilmente pode ser explicada em termos puramente linguísticos e gramaticais, pois a unidade intuitiva do discurso não está baseada na ligação conceitual entre palavras ou sentenças numa sequência textual, mas em condições referenciais (extensionais) (VAN DIJK, 2011[1992], p. 158).

Nessa mesma direção, seguem os estudos de Cavalcante et al.(2010) ao asseverar que a partir da perspectiva sociocognitiva e interacional, a coerência é estabelecida por um processo de inferência, para o qual concorrem as marcas linguísticas, a interação entre os co-participantes da enunciação e o contexto.

Para esses autores, o estabelecimento da coerência se dá, portanto, de forma dinâmica, não estando ela instalada a priori no texto. Essa noção de coerência ajusta-se à afirmação de que o aspecto interacional é inerente ao texto, desde que nele sejam introjetados dados pragmático-situacionais (CAVALCANTE et al., 2010, p. 243). O texto constitui-se, pois, como um jogo de atuação comunicativa que se projeta na materialidade linguística.

Os autores afirmam, também, que o redimensionamento dos processos referenciais e da noção de tópico discursivo amplia a noção de coesão. Assim, muito mais do que o mero emprego de elos na superfície textual, a coesão constitui "uma 
Linha D'Água (Online), São Paulo, v. 29, n. 1, p. 181-200, jun. 2016

articulação de todos os indícios cotextuais, e ao mesmo tempo, das inferências engatilhadas por eles" (CAVALCANTE et al., 2010, p. 255).

Vale ressaltar que, em seu trabalho, evidencia-se também a interdependência entre a coesão e a coerência, como postula Koch (2006). Cavalcante et al.(2010) asseveram que não é possível conceber a coerência sem admitir que ela esteja atrelada à noção de coesão, esta última concebida como "a articulação de relações semânticas, pragmáticas, discursivas, sociocognitivas, disparadas pelo gatilho do cotexto" (CAVALCANTE et al., 2010, p. 255).

Ao tratar da coesão como critério de textualização, Marcuschi (2008) considera que os processos coesivos estruturam a sequência [superficial] do texto, mas não são simplesmente princípios sintáticos. De acordo com o autor, esses processos constituem os padrões formais para transmitir conhecimentos e sentidos. É por isso, explica o linguista, que em alguns textos a coesão superficial não é necessária para a textualidade, embora ela não seja irrelevante. Nesses casos, no entanto, "há um imenso investimento de conhecimentos partilhados que supre a ausência de outros critérios" (MARCUSCHI, 2008, p. 106) e, nesse sentido, podemos dizer que a coesão é inferida a partir da coerência. Mais uma vez percebemos a interdependência dessas duas noções para a construção de sentidos do texto.

Essa possibilidade de ausência de marcas linguísticas para o estabelecimento da coesão, para a qual aponta Marcuschi (2008), também ocorre com as relações de coerência que devem ser concebidas como uma entidade cognitiva, que não possui "algum tipo de explicitude imediatamente visível" (MARCUSCHI, 2008, p. 122123). O autor assevera que a coerência não se dá como um movimento sucessivo de enunciado para enunciado, daí sua característica de ser uma realização mais global do que local, embora o linguista aponte que ela possa ter um desenvolvimento local.

Nessa mesma direção, e admitindo o texto como uma unidade significativa global, encontramos a noção de coerência como um princípio de interpretabilidade, em Bentes (2012, p. 276), respaldada pelos postulados de Charolles, da década de 1980. Para o linguista, confirma a autora, a princípio, todos os textos seriam aceitáveis, admitindo-se que um texto pode ser incoerente em/para determinada situação comunicativa. Segundo Koch e Travaglia (1995, p. 37), "o texto será incoerente se seu produtor não souber adequá-lo à situação, levando em conta intenção comunicativa, objetivos, destinatário, regras socioculturais, outros elementos da situação, recursos linguísticos etc. Caso contrário, será coerente".

Nesse sentido, estabelecemos o sentido global aos textos com que lidamos cotidianamente, não especificamente pela decodificação linguística, mas porque estamos imersos, inseridos na sociedade como um todo (BENTES, 2012, p. 277). De onde podemos concluir, de acordo com a pesquisadora, que o conhecimento 
Linha D'Água (Online), São Paulo, v. 29, n. 1, p. 181-200, jun. 2016

da situação comunicativa pode contribuir fortemente para a construção de um ou mais de um sentido global para o texto (BENTES, 2012, p. 279).

Além do conhecimento da situação comunicativa, a linguista considera conhecimento de mundo, conhecimento partilhado e inferências como fatores de coerência. Ao utilizar esses conhecimentos para a produção e recepção de textos, de acordo com Bentes (2012, p. 284), estamos lançando mão de estratégias cognitivas, que em sentido restrito "são aquelas que consistem na execução de algum cálculo mental por parte dos interlocutores” (KOCH, 1997, p. 29).

Podemos perceber, nos postulados até aqui apresentados, que fatores externos ao texto, implícitos e não expressos em sua superfície concorrem para o estabelecimento da coesão e da coerência. Além disso, os estudos desses autores confirmam a interdependência entre esses dois critérios e a assunção de que eles não correspondem a propriedades do cotexto, de forma imanente, e não são dependentes apenas de determinações linguísticas.

Dessa perspectiva, ocorre não só o redimensionamento dessas noções como também a complexidade do trabalho do produtor de textos escritos, o qual deve inscrever na materialidade linguística tanto conhecimentos de diversas ordens quanto vivências carregadas de suas experiências sociocultural e historicamente situadas.

Esses processos e sua atualização demandam uma orientação para a produção escrita que inclui ações respaldadas por aspectos teórico-metodológicos que se encontram ainda ausentes, em nosso entender, das atividades e práticas de ensino e de aprendizagem na escola. Destacamos, neste artigo, a referenciação como um dos processos de estruturação do texto, a que estão codeterminadas a coesão e a coerência, que se mantém distante da agenda da educação básica.

De acordo com Marcuschi (2006), ainda que a coerência seja construída em virtude de relações de sentido internas e externas ao discurso, estas seriam sempre mediadas por elos representados por proposições, fatos etc., em que a atividade referencial constituiria uma espécie de base. Para o linguista, "a referência providencia as pistas sugestivas para a produção de sentidos e a coerência é o aproveitamento dessas sugestões para a elaboração de sentidos" (MARCUSCHI, 2006, p. 19). Dessa forma, coerência e referenciação são atividades imbricadas e codeterminadas que se realizam tanto global quanto localmente. Nessa direção, Cavalcante, Custódio Filho e Brito (2014, p. 43) caracterizam a referenciação "como um processo importantíssimo para a manifestação da coerência".

Assumir a relação coerência/referenciação pode indicar um caminho para a produção e recepção de textos, no processo de ensino e de aprendizagem da produção escrita. Compreender como se dá o processo de referenciação no texto do aluno, para a produção de sentidos, pode determinar critérios diferentes para 
Linha D'Água (Online), São Paulo, v. 29, n. 1, p. 181-200, jun. 2016

a avaliação de uma redação quanto ao sucesso ou insucesso relativo ao estabelecimento da coerência e da coesão. Além de abrir possibilidades de intervenção da parte do professor. Voltaremos a essa questão nas considerações finais.

Por ora, retomamos a noção de referenciação de uma perspectiva sociocognitiva e interacional. Para Cavalcante et al.(2010), essa noção está constitutivamente ligada às situações em que ela se desenvolve, e o referente é um objeto de discurso que não se relaciona apenas às marcas co-textuais explícitas, mas configura-se como uma entidade também construída na interação e representada na mente dos sujeitos da enunciação. Nesse sentido, vale retomar o que atesta Marcuschi (2006) ao relacionar coerência, referenciação e objeto de discurso. Para esse autor, a "coerência é o que deve acontecer quando introduzimos um certo objeto de discurso e depois pretendemos prosseguir com ele naquele discurso" (MARCUSCHI, 2006, p. 17).

A esse respeito, Marcuschi (2007, p. 79) defende que "a referenciação é um ato de construção criativo e não um simples ato de representação ou de designação extensional de uma expressão no mundo extra-mental”.

Ao analisar a relação da referenciação com a coerência, deve-se considerar que o texto se constrói e progride com base em dois processos gerais: progressão referencial e progressão tópica, conforme assevera Marcuschi (2006, p. 21).

Neste trabalho, vamos nos ater a evidenciar a relação entre coerência e coesão relacionadas à progressão referencial, definida, nas palavras de Marcuschi (2006, p. 21) como introdução, identificação, preservação, continuidade e retomada de referentes textuais, as quais correspondem a estratégias de designação de referentes, formando o que se pode chamar de cadeia referencial. A progressão referencial se dá, pois, com base numa complexa relação entre linguagem, mundo e pensamento estabelecida no discurso.

Marcuschi (2008, p. 109) oferece uma visão geral de estratégias de organização referencial compondo um quadro das principais formas que operam nesse sistema dividindo-as em:

- formas remissivas referenciais - todos os elementos linguísticos que estabelecem referências a partir de suas possibilidades referidoras, incluídos aqui sinônimos, grupos nominais definidos etc.

- formas remissivas não-referenciais - são aquelas que não possuem autonomia referencial (só referem concretamente), como os pronomes e artigos. 
Linha D'Água (Online), São Paulo, v. 29, n. 1, p. 181-200, jun. 2016

Mais do que aprofundar essa diferença, neste trabalho ressaltamos a importância das escolhas lexicais tendo em vista a construção da coesão e da coerência na produção escrita de alunos.

A escolha de formas nominais constitui para Koch e Penna (2006) uma maneira de os usuários da língua realizarem seu projeto de dizer e um meio estratégico de operar com objetos de discurso. Esse processo permite inserir os interlocutores em uma moldura comum de conhecimentos compartilhados, além de confirmar ou frustrar as expectativas do leitor, abrindo espaço para uma negociação na construção de sentidos (KOCH e PENNA, 2006, p. 25).

Em síntese, as autoras procuram evidenciar que:

i. o discurso constrói o objeto a que faz remissão;

ii. a construção desse objeto se dá de maneira estratégica, visando o projeto de dizer;

iii. as estratégias de construção se dão de maneira interativa entre os interlocutores, que envolve conhecimentos compartilhados numa dada moldura sociocognitiva;

iv. as estratégias de progressão referencial são responsáveis pelos dois movimentos de estruturação do texto - prospecção e retroação que se realizam e, a nosso ver, estão intimamente relacionados à construção da coesão e da coerência.

Vale ressaltar que na exemplificação, que ora apresentamos no desenvolvimento deste trabalho, tratamos da construção de sentidos em redações de vestibulares explorando de maneira conjunta os dois critérios de textualização, coesão e coerência, codeterminados à referenciação.

Ratificam essa nossa decisão as palavras de Bentes (2012): "os conceitos de coerência e coesão textuais são imprescindíveis para aqueles que pretendem trabalhar com níveis textuais e/ou discursivos de realização da língua" (BENTES, 2012, p. 297). A linguista aponta, ainda, a importância dos estudos voltados para as análises do texto/discurso e o desenvolvimento da competência textual e/ ou discursiva na escola, campo em que se insere o tema deste artigo. 
Linha D'Água (Online), São Paulo, v. 29, n. 1, p. 181-200, jun. 2016

\section{Exemplificação: a construção da coesão e da coerência em redações de vestibular}

Tomamos, a título de exemplificação, duas redações de vestibular, com o intuito de mostrar como o uso de formas nominais na referenciação pode corroborar para a construção da coesão e da coerência e, consequentemente, para a produção de sentidos. Procuramos mostrar como as escolhas lexicais e orientações semânticas norteiam a produção de sentidos relacionada a um projeto de dizer, de uma perspectiva sociocognitiva e interacional, em que não se leva em conta apenas os elementos linguísticos. Defendemos que esse processo pode auxiliar a elaborar uma produção escrita bem estruturada no que se refere à construção de um texto coeso e coerente.

Para isso, cotejamos duas redações, evidenciando os aspectos elencados acima, mostrando como uma é bem sucedida e a outra apresenta falhas na produção de sentidos, o que interfere diretamente na viabilização do projeto de dizer do produtor.

Justificamos a escolha de redações de vestibular, por ser essa a etapa da educação em que os alunos já completaram o período de escolarização básica. A expectativa é a de que, nesse momento, os candidatos ao ensino superior sejam tanto proficientes na escrita quanto capazes de desenvolver um texto adequado à proposta de produção escrita elaborada pela instituição responsável pelo exame vestibular, sobre um determinado tema.

A proposta escolhida é da PUC-SP, para a prova de 2014, cujo tema é o anonimato na internet. A proposta envolve um texto de referência e a comanda, isto é, a proposta propriamente dita, que se compõe de algumas orientações quanto à forma de desenvolver o texto solicitado, aos procedimentos necessários e aos critérios de avaliação. $\mathrm{O}$ texto de referência consiste num artigo de opinião, escrito pelo jornalista Eugênio Bucci, que circula em seu blog "A Varanda", intitulado "Cyberanonimato". O texto foi adaptado para a proposta desse exame de vestibular. ${ }^{1}$

Vale destacar como positivo nessa proposta tanto a adequação do tema, por estar vinculado e próximo à realidade dos jovens dessa faixa etária, quanto o texto de referência. Esse último possibilita uma reflexão ao expor argumentos a favor e contra o anonimato na internet, conferindo maior liberdade para o candidato posicionar-se, concordando ou discordando, levando em conta seus conhecimentos prévios e vivências.

Selecionamos trechos iniciais de duas redações para a exemplificação da análise: um modelo bem sucedido (redação 1) e outro mal sucedido (redação 2),

1 O texto de referência e a proposta de redação do exame de vestibular da PUC-SP (2014) estão disponíveis para leitura em: http://www.cpv.com.br/cpv_vestibulandos/redacoes/puc/ PUCSP_2014.pdf. Acesso em: 22 fev. 2016. 
Linha D'Água (Online), São Paulo, v. 29, n. 1, p. 181-200, jun. 2016

destacando a laboração do processo de referenciação, em sua relação com a construção da coesão e da coerência, no que diz respeito à configuração de um projeto de dizer e ao atendimento efetivo à proposta.

Para isso, destacamos o uso de formas nominais de que os produtores lançam mão para a construção da representação de objetos de discurso, estabelecendo a progressão referencial, de modo a estruturar o texto de forma coesa e coerente. Apontamos, também, como, por meio da escolha de formas nominais, o produtor de texto realiza seu projeto de dizer, interage com o leitor compartilhando conhecimentos e sugere pistas delineando para o seu interlocutor um caminho para a produção de sentidos. A seguir, apresentamos o parágrafo inicial de cada redação e sua análise:

\section{Redação 1}

\section{Título - Ode à liberdade de expressão}

Desconfiança e insegurança. É o que sentiria um comprador online se o seu fornecedor não tivesse nome nem endereço. Quem confiaria? $\mathrm{O}$ anonimato, embora tenha sido utilizado com ótimas finalidades em algumas épocas e lugares, até em épocas de Ditadura e repressão, hoje, está aliado, principalmente na internet, a ferir imagens, denegrir e até a práticas de crimes mais pesados. Por isso, há que se fazer uma reflexão acerca do assunto e saber o objetivo e uso deste, garantindo sempre o respeito alheio, integridade e dignidade das pessoas a quem este recurso atinge.

Na redação 1, vale observar que logo no início o produtor do texto usa a estratégia de introduzir o objeto de discurso "anonimato" por meio de uma exemplificação, remetendo à prática de compra na internet, compartilhando conhecimentos/ vivências com o leitor e, ao mesmo tempo, convocando-o para o texto por meio de uma pergunta retórica - "quem confiaria?". Na sequência do texto, o produtor vai construindo uma representação para esse objeto de discurso, "anonimato", pois utiliza uma expressão nominal que faz remissão a ele pelas atribuições "nem nome nem endereço". Só então introduz o termo "anonimato" que será retomado na sequência do texto por: "deste", "o assunto" e "este recurso".

Como nosso objetivo são as formas nominais, destacamos a retomada de "anonimato" pelos substantivos "assunto" e "recurso". O uso de "assunto" permite inferir que o produtor considera o anonimato um tema próprio ao debate, ou, ainda, um tema de conhecimento público. Vale ressaltar que a escolha de "assunto" sinaliza uma maior neutralidade do produtor na representação que constrói para o objeto de discurso "anonimato", pois este é um termo mais isento de carga 
valorativa, se o compararmos a substantivos como "problema" ou "questão", que poderiam ser escolhas do produtor. Já no uso do substantivo "recurso" percebe-se que o produtor relaciona o "anonimato" a algo de que se lança mão para alguma ação, que serve para agir. O termo "recurso" sintetiza as duas possíveis ideias de ação pelo anonimato, as quais o produtor expôs anteriormente no texto: "ótimas finalidades na Ditadura e repressão" (valoração positiva) e "ferir imagens, denegrir e práticas de crimes" (valoração negativa).

Colaboram também para construir a representação desse objeto de discurso e para delinear um caminho para a produção de sentidos as formas nominais desconfiança, insegurança, reflexão, objetivo, respeito, dignidade e integridade. A representação do objeto de discurso "anonimato" está construída nesta sequência: gera desconfiança e insegurança, necessita reflexão (como assunto) e seu objetivo (como recurso) deve garantir respeito, dignidade e integridade (às pessoas). Essas escolhas mostram a disposição do produtor de levar em conta vários aspectos para construir a representação do objeto de discurso "anonimato", admitindo prós e contras.

Pode-se perceber, ainda, que o produtor lança mão de várias formas nominais em que fundamenta o seu projeto de dizer e são elas que delineiam um caminho para a produção/atribuição de sentidos. O leitor é convocado a interagir, pois há expectativas do produtor em relação a conhecimentos compartilhados (ditadura/ repressão) e práticas sociais (compra na internet).

Pode-se ainda dizer que, embora a construção de frases e coesão local em alguns momentos deixe lacunas no texto, a progressão referencial garante a estruturação coesa e coerente do texto de maneira global. O produtor constrói uma representação para o objeto de discurso anonimato e o mantém presente no texto. Isso ressalta a importância do processo de referenciação, do qual destacamos nessa análise o uso das formas nominais, como uma estratégia textual-discursiva essencial para a realização bem sucedida dos dois critérios de textualização: a coesão e a coerência.

\section{Redação 2 \\ Sem título}

Atualmente, com a internet a facilidade de poder expressar a sua opinião de modo anônimo se tornou mais comum, o que resulta em várias pessoas criticando, debatendo, discutindo sobre um interesse em comum, sendo este geralmente algo que todos compartilham e que afete de um modo crítico a vida de todos $\underline{\mathrm{O} \text { anonimato }}$ consegue proteger aqueles que criticam os opressores, pois os opressores muitas vezes não deixam os outros terem o seu direito a liberdade de expressão, garantindo então segurança para aqueles que são contrários aos ideais 
Linha D'Água (Online), São Paulo, v. 29, n. 1, p. 181-200, jun. 2016

"dominantes" e permitindo através da internet que mais pessoas se identifiquem com esses ideais.

Em contraposição, o que foi observado na primeira redação não ocorre na redação 2. Podemos perceber que o produtor inicia o texto fazendo referência a "anonimato" sem usar uma forma nominal. O objeto de discurso "anonimato" é introduzido pelo produtor do texto por uma expressão adverbial "de modo anônimo" ligada à ação de "expressar sua opinião".

Destacamos que o produtor enfatiza e mantém no texto a ação "expressar opinião sobre um interesse comum" e não o objeto de discurso "anonimato", que parece apenas servir a essa ação. Não é o objeto de discurso "anonimato" que orienta a produção de sentidos no texto.

Podemos observar também o uso constante de pronomes e não de formas nominais para as retomadas de objetos de discurso. No caso de "interesse comum", sua retomada se dá por meio de pronomes indefinido e demonstrativo, respectivamente, "algo" e "este", o que produz uma indefinição generalizada, uma frouxidão no texto, que não orienta a produção/atribuição de sentidos.

Da mesma forma, os agentes da ação "expressar opinião", as pessoas, também são retomados por pronomes indefinidos "todos", "aqueles", "outros".

O objeto de discurso "anonimato", em sua forma nominal, só aparece no segundo parágrafo relacionado "à proteção de expressão de ideias", "à segurança das pessoas", mas não é mais retomado por nenhuma outra forma nominal. Mais uma vez reforça-se a ideia de que o produtor não tem definido em seu projeto de dizer nem o objeto de discurso "anonimato" nem a construção de uma representação para ele, mas centra-se na ideia da ação que ele possibilita, ou seja, a expressão de opiniões pela internet.

Notamos, ainda, que a ausência de formas nominais na laboração da referenciação produz um discurso vago, que não fundamenta um projeto de dizer, propõe pouca interação com conhecimentos partilhados do leitor, além de oferecer poucas pistas para que o leitor possa seguir um caminho para a construção de sentidos.

Vale observar sobre a redação 2 que, embora não haja questões evidentes em relação à coesão e coerência locais, o produtor de texto não constrói uma progressão referencial baseada em um projeto de dizer que atenda de forma efetiva ao tema da proposta (anonimato na internet) e que garanta a estruturação coesa e coerente do texto, de maneira global. Sendo assim, o produtor embora construa representações para o objeto de discurso anonimato, não o mantém em foco no decorrer do texto. 
Justificamos que, por delimitação de espaço, restringimos nossa análise a trechos iniciais das redações. Podemos afirmar, no entanto, que essa breve análise permite indicar o que ocorre ao longo das duas redações (vide anexos 1 e 2). No decorrer do texto, confirma-se o que descrevemos para esses trechos iniciais, tanto no desenvolvimento quanto na conclusão de cada uma delas.

Essa exemplificação atende a nosso intuito de mostrar que a análise da coesão e da coerência, como critérios de textualização, interdependentes e codeterminados à referenciação, apesar de estar atrelada à materialidade linguística, permite evidenciar estratégias e propósitos implícitos ao projeto de dizer do produtor do texto.

Além disso, essa análise evidencia tanto a possibilidade de balizar a relação de interação que se estabelece entre o produtor do texto e seu interlocutor por meio do compartilhamento de conhecimentos quanto o delineamento de um caminho para a atribuição de sentidos, a partir da estruturação de texto proposta pelo produtor.

Em nossas considerações finais, apontamos como essa nova visada das noções de coesão e de coerência, de uma perspectiva sociocognitiva e interacional, pode trazer avanços para o ensino e aprendizagem da escrita, relativos ao desenvolvimento da proficiência escritora, no período de escolarização básica.

\section{Conclusão}

Neste artigo, procuramos mostrar como os atuais estudos teóricos da LT, relativos aos critérios de textualização da coesão e da coerência, em sua codeterminação com a referenciação, podem contribuir para o avanço do ensino e da aprendizagem da escrita.

Os estudos apresentados na fundamentação teórica (segunda parte deste artigo), ao evidenciar que aspectos sociocognitivos e interacionais estão implicados no estabelecimento da coesão e da coerência, pressupõem uma concepção dialógica, heterogênea e interativa da língua; uma noção de texto que engloba aspectos linguísticos e contextuais; além da participação de sujeitos ativos, situados sociocultural e historicamente, e inseridos numa dada prática social.

Sendo assim, para o estabelecimento de um texto coeso e coerente concorrem não só dados do cotexto, mas também aspectos da interação entre os sujeitos da enunciação, a ativação de modelos cognitivos armazenados na memória e elementos contextuais, em particular de ordem sociocognitiva e interacional.

Acreditamos, por conseguinte, que nessa perspectiva se amplia bastante a tarefa do professor, ao analisar textos mal sucedidos de alunos em relação à coesão e à coerência, os quais oferecem dificuldade para a atribuição de sentidos. Compreendemos ser necessário que o docente considere não só os problemas que aparecem explicitamente na materialidade linguística, mas também que aprofunde 
Linha D'Água (Online), São Paulo, v. 29, n. 1, p. 181-200, jun. 2016

sua análise em relação aos aspectos sociocognitivos e interacionais, procurando especificar onde se encontra a dificuldade do aluno em relação a esses dois critérios de textualização, na produção escrita de seu texto.

É preciso que, como leitor experiente, o professor, em suas devolutivas e orientações, proponha questões que façam o aluno pensar, por exemplo, sobre os modelos cognitivos que possui sobre determinado tema ou gênero e sobre aqueles que precisa construir ou ativar; sobre o contexto em que se insere a sua enunciação; ou ainda, sobre o compartilhamento de conhecimentos com seu interlocutor, necessário para a compreensão dos implícitos do texto.

Essas são apenas algumas possibilidades de intervenção que elencamos serem necessárias para que o professor realmente oriente o aluno para a construção da coesão e da coerência de seu texto, provocando mudanças efetivas em sua aprendizagem e promovendo a proficiência escritora.

Acreditamos que, ao redimensionar a noção de coesão e de coerência, da perspectiva sociocognitiva e interacional, amplia-se também o escopo de atuação para o ensino e a aprendizagem da escrita. Afinal, nessa perspectiva, escrever é um processo complexo que se realiza na interação entre sujeitos sociais que operam cognitivamente com o conhecimento e com a linguagem.

\section{Referências}

BEAUGRANDE, Robert. New Foundations for a Science of Text and Discourse: Cognition, Communication and the Freedom of Access to knowledge and Society. Norwood, New Jersey, Ablex Publishing Corporation, 1997.

BENTES, Anna Christina. Linguística Textual. In: MUSSALIM, Fernanda; BENTES, Anna Christina. Introdução à linguística: domínios e fronteiras. São Paulo: Cortez, 2012, p. 261-301.

BENTES, Anna Christina; REZENDE, Renato Cabral. O texto como objeto de pesquisa. In: GONÇALVES, Adair Vieira; GÓIS, Marcos Lúcio de Sousa (Orgs). Ciências da linguagem: o fazer cientifico. Campinas: Mercado de Letras, 2014, v.2, p. 137-176.

BRANDÃO, Helena Nagamine. (Org.). Gêneros do discurso na escola. São Paulo: Cortez, 2003, v. 5, (Coleção Aprender e ensinar com textos).

CAVALCANTE, Mônica Magalhães et al. Dimensões textuais nas perspectivas sociocognitiva e interacional. In: BENTES, Anna Christina; LEITE, Marli Quadros (orgs.). Linguistica de texto e análise da conversação: panorama das pesquisas no Brasil. São Paulo: Cortez, 2010, p. 225-261. 
Linha D'Água (Online), São Paulo, v. 29, n. 1, p. 181-200, jun. 2016

CAVALCANTE, Mônica Magalhães; CUSTÓDIO FILHO, Valdinar; BRITO, Mariza Angélica Paiva. Coerência, referenciação e ensino. São Paulo: Cortez, 2014.

DIJK, Teun Adrianus van. Modelos na memória - O papel das representações da situação no processamento do discurso. In: Cognição, discurso e interação. 7.ed. São Paulo: Contexto, 2011[1992], p. 158-179.

GOMES-SANTOS, Sandoval Nonato et al. A contribuição da(s) teoria(s) do texto para o ensino. In: BENTES, Anna Christina; LEITE, Marli Quadros (orgs.). Linguística de texto e análise da conversação: panorama das pesquisas no Brasil. São Paulo: Cortez, 2010, p. 315-353.

KOCH, Ingedore Villaça. O Texto e a construção dos sentidos. São Paulo: Contexto, 1997. Introdução à linguística textual. São Paulo: Martins Fontes, 2006. As tramas do texto. São Paulo: Contexto, 2014[2008].

KOCH, Ingedore Villaça; ELIAS Vanda Maria. Ler e escrever - estratégias de produção textual. São Paulo: Contexto, 2011.

KOCH, Ingedore Villaça; PENNA, Maria Angélica de Oliveira. Construção/reconstrução de objetos-de-discurso: manutenção tópica e progressão Textual. Cadernos de estudos linguísticos. Campinas, v.48, n.1, 2006, p. 23-31.

KOCH, Ingedore Villaça; TRAVAGLIA, Luís Carlos. Texto e coerência. São Paulo: Cortez, 1995.

MARCUSCHI, Luiz Antônio. Referenciação e progressão tópica: aspectos cognitivos e textuais. Cadernos de estudos linguísticos. Campinas, v.48, n.1, p. 7-22, 2006.

Cognição, linguagem e práticas interacionais. Rio de Janeiro: Lucerna, 2007.

Produção textual, análise de gêneros e compreensão. São Paulo: Parábola Editorial, 2008.

ROJO Roxane; CORDEIRO Glaís Sales. Apresentação: gêneros orais e escritos como objetos de ensino: modo de pensar, modo de fazer. In: ROJO Roxane. e CORDEIRO Glaís Sales. Gếneros orais e escritos na escola (orgs). Campinas, SP: Mercado de Letras, 2004, p. 7-18.

Recebido: 15/03/2016

Aprovado: 11/04/2016 
Linha D'Água (Online), São Paulo, v. 29, n. 1, p. 181-200, jun. 2016

\section{Anexo 1 - redação $1^{2}$ \\ Ode à liberdade de expressão}

Desconfiança e insegurança. É o que sentiria um comprador_online se o seu fornecedor não tivesse nome nem endereço. Quem confiaria? $\mathrm{O}$ anonimato, embora tenha sido utilizado com ótimas finalidades em algumas épocas e lugares, até em épocas de Ditadura e repressão, hoje, está aliado, principalmente na internet, a ferir imagens,_denegrir e até a práticas de crimes_mais pesados. Por isso, há que se fazer uma reflexão acerca do assunto e saber o objetivo e uso deste, garantindo sempre o respeito alheio, integridade e dignidade das pessoas a quem este recurso atinge.

$\mathrm{Na}$ área constitucional e no âmbito da legalidade, no Brasil, o anonimato é tido como crime, porém, na internet, o que se vê, é uma quantidade imensa de possibilidades de se navegar sendo "público" mas ao mesmo tempo sem expor nome, nem endereço, sendo assim, uma farsa. Se ao menos fossem anônimos escritores em blogs, não seria alarmante, mas a realidade, sim, é. Além dos atos e crimes contra a dignidade, como xingamentos, mentiras, preconceito, homofobia, há também aqueles de maior peso, com a venda e tráfico das drogas anônimo, além dos canais intranet, onde existem incontáveis formas de crimes anônimos: venda de pessoas, armas, droga e até "dicas" de suicídio e assassinato.

Em outros tempos, crimes de tão "fácil acesso" como hoje, não eram possíveis. A comunicabilidade era bem menor e até certa época tudo estava confinado à Igreja e ao dogmatismo religioso. Muitos filósofos iluministas, para criar e disseminarem suas ideias e ideais utilizavam-se do anonimato para não irem à forca, guilhotina. A própria revolução russa teve seu início no anonimato dos "Soviets" e ocorreu por conta da comunicação anônima. Templários, mais tarde maçonaria e até a sociedade gnóstica até hoje sobrevive por conta do anonimato pregado em outras épocas. Porém eram épocas de construção de liberdade, busca por ideais e condições dignatárias de sobrevivência.

Hoje se tem a liberdade e o homem não sabendo o que fazer com ela, a mal utiliza, dando fins trágicos, por isso Voltaire disse que conhece o homem realmente quando este tem poder e o que faz com ele. Por isso faz-se necessário que os crimes de internet sejam punidos e o anonimato findado, quando o uso for impróprio e em rede pública, além da conscientização que todos devem fazer do uso deste, tendo em conta que assim como a Anomia descaracteriza o Estado democrático de direito, o Anonimato descaracteriza a Liberdade Individual e respeito ao próximo.

2 As redações originais foram digitadas, de modo a facilitar a leitura e a análise. Após a digitação o material passou por cotejamento e revisão, a fim de garantir sua autenticidade. 
Linha D'Água (Online), São Paulo, v. 29, n. 1, p. 181-200, jun. 2016

\section{Anexo 2 - redação 2}

\section{Sem título}

Atualmente, com a internet a facilidade de poder expressar a sua opinião de modo anônimo se tornou mais comum, o que resulta em várias pessoas criticando, debatendo, discutindo sobre um interesse em comum, sendo este geralmente algo que todos compartilham e que afete de um modo crítico a vida de todos

$\mathrm{O}$ anonimato consegue proteger aqueles que criticam os opressores, pois os opressores muitas vezes não deixam os outros terem o seu direito a liberdade de expressão, garantindo então segurança para aqueles que são contrários aos ideais "dominantes" e permitindo através da internet que mais pessoas se identifiquem com esses ideais.

$\mathrm{O}$ anonimato consegue proteger aqueles que criticam os opressores, pois os opressores muitas vezes não deixam os outros terem o seu direito a liberdade de expressão, garantindo então segurança para aqueles que são contrários aos ideais "dominantes" e permitindo através da internet que mais pessoas se identifiquem com esses ideais.

Porém há aqueles que usam o anonimato não como forma de expor seus ideais, mas sim para depredar os ideais alheios com a função de causar o caos e a discórdia, usando assim o anonimato de forma ruim pata a sociedade.

Mas o anonimato já se provou como uma forma de garantir direitos, como, por exemplo o grupo Anonymous, que durante rebeliões de países contra seus governos veio para reivindicar direitos para a população e se não fosse graças ao anonimato eles teriam sido caçados por aqueles que oprimiam a população

Logo o anonimato deve ser algo que continua presente em nossas vidas, apesar de seu potencial depredativo ele possui uma capacidade muito maior de proteção, segurança e sobrevivência daqueles que não podem expressar seus ideais. 